Chapman University

Chapman University Digital Commons

$9-27-2018$

Positive Affect and Health: What Do We Know and Where Next Should We Go?

Sarah D. Pressman

Brooke N. Jenkins

Judith T. Moskowitz

Follow this and additional works at: https://digitalcommons.chapman.edu/psychology_articles

Part of the Biological Psychology Commons, Health Psychology Commons, Other Psychology Commons, Personality and Social Contexts Commons, and the Social Psychology Commons 


\section{Positive Affect and Health: What Do We Know and Where Next Should We Go?}

\section{Comments}

This is a pre-copy-editing, author-produced PDF of an article accepted for publication in Annual Review of Psychology, volume 70, in 2019.

Posted with permission from the Annual Review of Psychology, Volume 70, by Annual Reviews, https://doi.org/10.1146/annurev-psych-010418-102955

\section{Copyright}

Annual Reviews 


\section{Positive Affect and Health: What Do We Know and Where Next Should We Go? \\ Sarah D. Pressman ${ }^{1}$, Brooke N. Jenkins ${ }^{2}$, \& Judith T. Moskowitz ${ }^{3}$ \\ ${ }^{1}$ University of California, Irvine \\ ${ }^{2}$ Chapman University \\ ${ }^{3}$ Northwestern University}

Acknowledgements. The authors thank Amanda Acevedo, Desi Chase, Marie Cross, and John Hunter for comments on this manuscript, and the many undergraduate students in our laboratories who contributed to the literature review, especially Rebecca Corona. Dr. Pressman's time was partially supported by an award from the AXA Research Fund.

Keywords: happiness, calm, vigor, positive emotion, health, illness, stress 


\begin{abstract}
Positive affect (PA) is associated with better health across a wide range of physical health outcomes. This review reflects on why the study of PA is an essential component to our understanding of physical health and expands upon pathways that connect these two variables. To encourage forward movement in this burgeoning research area, measurement and design issues in the study of PA and health are discussed, as are the connections between PA and a range of different health outcomes. Plausible biological, social, and behavioral pathways are detailed that allow for positive feelings to "get under the skin" and influence physical wellness, framed in the context of several theoretical models. Finally, new directions for the field as well as important methodological and interpretative considerations that are essential in moving this important research area forward are explored.
\end{abstract}




\section{INTRODUCTION}

Humans have a strong desire to be both healthy and happy. This public want is echoed by advertising campaigns focused on being at the "corner of happy and healthy" (Walgreens ${ }^{\mathrm{TM}}$ ) and best-selling book

lists consistently featuring literature on these topics. Recently, there has been a surge of research tackling these two topics as well, including studies testing the complex interconnections between these variables. The 13-year old seminal review of research in this area (Pressman \& Cohen 2005) included approximately 70 studies of health outcomes like mortality, disease morbidity, disease severity, survival after disease diagnosis, and pain, as well as over 100 studies on physiological outcomes. Since this point, the literature has grown tremendously, including many important conceptual replications of early work.

Several more recent comprehensive qualitative and quantitative reviews have similarly indicated that PA is associated with health benefits such as a longer life (Chida \& Steptoe 2008; Diener \& Chan 2011; Zhang \& Han 2016), cardiovascular health (Boehm \& Kubzansky 2012), and better outcomes in chronic diseases like cancer and HIV (Hernandez et al. 2018). Taken together, there is now impressive evidence that PA short term states and long-lasting traits have extensive correlations with an array of health and health-relevant outcomes. Furthermore, prospective longitudinal studies of health and experimental lab affect manipulations examining physiological change hint at causal effects of PA. However, many questions remain. For example, what underlies inconsistencies in the literature? What are the mechanisms connecting PA and health? And, importantly, can PA interventions improve health? The goal of this review is to delve into these issues, with a focus on important study characteristics and theories that help unpack these questions. A final objective is to help researchers design and interpret their work in a way that will deepen the literature and propel the field forward.

Due to the wide array of assessment approaches in this field, it is critical to first discuss central measurement issues, both for PA and for health, and then provide a broad overview of recent evidence connecting these variables. Next, theories that indicate how PA can "get under the skin" to influence health are explored alongside evidence supporting hypothesized pathways. The burgeoning literature examining PA-increasing interventions with the hope of maintaining or improving physical health is also 
described and evaluated. Finally, the most pressing new directions for the field of PA and health are outlined to demonstrate important ways to fill gaps in the literature.

\section{MEASUREMENT CONSIDERATIONS}

\section{Positive Affect}

PA is generally described as the experience of pleasurable emotions such as happiness, joy, excitement, enthusiasm, calm, and contentment. PA measures vary in their inclusion of different affective words and their assessed time frames. Thus, measurement considerations like these are discussed below as important issues arise depending on the approach taken.

Time frame. One surprisingly ignored topic when selecting a measure in PA-health studies is the time period over which participants are asked to report their experiences of PA. Self-reported PA assessments begin with an interval to evaluate such as "the current moment" (i.e., emotion or state affect), "the last week" (i.e., positive mood), or "in general" (i.e., trait affect). There is abundant evidence that state affect can alter in-the-moment physiological factors like cardiovascular, immune, and endocrine outcomes as well as health behaviors (see pathways sections below). Thus, for brief experimental and diary studies on health-relevant mechanisms, state PA is the appropriate measurement choice. In contrast, when considering distant outcomes (e.g., mortality), trait affect has ample opportunities to repeatedly influence factors like behavior, physiology, and social relationships over time, making it the logical choice. It is not uncommon, however, for researchers to ask questions about state affect (e.g., a single day's happiness) and then connect it to outcomes assessed years later (e.g., mortality; Steptoe \& Wardle 2011). Although from a mechanistic standpoint it is unexpected that feeling positive on a single day would foretell health decades later, short term assessments do sometimes predict distant outcomes. This is likely due to their statistical, albeit noisy, overlap with trait affect. Thus, prior to choosing an affect assessment, researchers need to carefully consider whether state or trait is the best match for the timing of PA's association with the health outcome. This also casts a different light on a common practice of contrasting trait “eudaimonia" (e.g., life meaning, purpose) assessments against state PA assessments (i.e., hedonia) with the intent of arguing that one matters more than the other in the context of health (e.g., Friedman et al. 
2017). Based on the explanation above, longer lasting measures of trait positivity should (and do) consistently outperform transient state affect. While it is a critical step in this field to determine which types of affective constructs matter for different outcomes, a more constructive future approach would be to contrast equivalent time assessments.

Number and content of items. PA is typically measured using adjective rating scales with terms representing specific affective experiences (e.g., happy, excited, calm, etc.). Participants rate how much each adjective represents how they currently feel or felt over a certain time frame. Since there are many affectively oriented scales to choose from, a careful choice is warranted. Picking a measurement tool should be guided by underlying conceptual models and a thoughtful exploration of what the best choice might be. What is more common is an atheoretical approach constrained by what has been used before and/or what is available in an existing data set. For example, the 20-item Center for Epidemiological Studies-Depression (CES-D) scale (Radloff 1977) is repeatedly employed in PA-health research, not because it is an ideal assessment of PA, but because it has been frequently included in large medical datasets and has a four-item positive subscale. This positive subscale combines affect (happy) and nonaffect items (life enjoyment, hope, and esteem), complicating the interpretation of the results. Similarly, many studies utilize single-item PA assessments (e.g., Liu et al. 2016) such as "How often do you feel happy?". While time efficient, one item cannot capture all of PA and may miss true effects of PA on assessed outcomes.

When possible, it is best to use well designed and validated affect assessments. For example, the 20-item Positive and Negative Affect Schedule (PANAS; Watson et al. 1988) is frequently selected because it has the desirable feature of PA and negative affect (NA) being statistically separable. This is important given the frequent question of whether PA effects are simply due to a lack of NA. Separability of constructs allows for simultaneous assessment in analyses. While an excellent measure in terms of psychometric properties, what many researchers do not consider is that the underlying theoretical orientation of this measure is that PA is pleasure and high arousal (e.g., alert, excited). Thus, if a researcher is interested in calm or happiness, the PANAS is inappropriate. Instead, a dimensional model 
(e.g., Russell 1980) where PA and arousal are separable (e.g., high, mid, and low arousal; Cohen et al. 2003; Usala \& Hertzog 1989) is more suitable. This is especially important given evidence that arousal types are distinctly associated with health outcomes. For example, a growing body of work shows that it is the higher arousal components of PA most tied to lower risk of death (Petrie et al. 2018; Pressman \& Cohen 2012) and disease (Shirom et al. 2010). While calm has been rarely associated with health and physiology (see Shirom et al. 2009 for an exception in blood lipids), this may be due to a lack of attention to cultural norms that prioritize different arousal levels of PA (e.g., Sims \& Carstensen 2014). Needless to say, researchers should make an informed decision about what measure is most suitable for their study design and objectives and consider the examination of subtypes of affect. When there is no ability to choose a measure a priori, researchers can consider breaking down larger constructs into single items (e.g., discrete emotions) to explore active sub-ingredients. Finally, researchers should not assume interchangeability of PA measures and clearly acknowledge limitations of the measure they use. Non-self-report assessments of PA. Many have advocated for the use of multiple and/or alternative methods beyond self-report in affective science due to issues such as self-presentation bias or differences in response styles. One example of this is seen in studies that examine affectively laden language use. Utilizing this method, researchers have found that higher numbers of high arousal PA words in autobiographies of well-known psychologists were associated with longer life (Pressman \& Cohen 2012) and that positive Twitter language correlates with lower cardiovascular disease at the county level (Eichstaedt et al. 2015). While language use is clearly something different than self-report (Pennebaker et al. 2003), it helps provide a complementary source of evidence as it removes many forms of reporting bias since participants rarely know what is being studied or even that they are being studied.

Smiling, especially Duchenne smiling (expression that activates both orbicularis oculi muscles around the eyes and zygomaticus major muscles in the cheeks), is another alternative method to get at PA. Duchenne smiling is positively correlated with self-reports of PA and is tied to neurological changes consistent with PA (Ekman \& Davidson 1993). While smiles are rarely studied in the context of health, studies have found that covert manipulations (Kraft \& Pressman 2012) and natural occurring smiles 
(Fredrickson \& Levenson 1998) predict better cardiovascular recovery following stress, a health-relevant outcome. Additionally, naturally occurring smiles during structured interviews (among other PA indicators) were associated with a $22 \%$ decreased risk of heart disease over a 10 -year follow-up (Davidson et al. 2010). Smiling in professional baseball player cards was not correlated with mortality in a recent study (Dufner et al. 2017) indicating a need to consider the source and meaning of smiles since it is likely that public photographs may represent something different (e.g., self-presentation preferences, agreeableness) than lab-based, experimentally manipulated, and naturally occurring smiles. Despite their limitations, these approaches are novel and provide convergent validity for self-report findings as well as plausible unique pathways to health (e.g., via differences in expression versus suppression, direct nerve stimulation to peripheral physiology via facial expression; Pressman \& Cross in press). Thus, we advocate for these and other novel approaches to PA assessment (e.g., behavioral coding, observer reports, neural/physiological indicators) in addition to self-report approaches.

\section{Physical Health}

While the World Health Organization (Grad 2002) describes health as something more than the absence of disease or infirmity, there is no single objective biological measure of health, so researchers rely on mortality, disease and disease-relevant outcomes. Changes in physiology, while health relevant, are rarely at a magnitude that would have health-altering impacts in the moment. Thus, a change in cortisol or immune activity during an emotion induction should not be considered a physical health outcome, but rather a possible pathway to health.

One of the more pressing issues to consider is the item overlap between measures of health and measures of PA, which can artificially inflate the statistical associations between PA and health.

Specifically, some measures of self-reported health utilize words like vigor, activity, and energy to assess wellness (e.g. SF-36; Ware \& Sherbourne 1992). These same items are used in many popular PA scales (e.g., the Profile of Mood States [McNair et al. 1971], the PANAS [Watson et al 1988]). As a result, it is critical for researchers to carefully covary measures of objective and/or perceived health at baseline, especially when assessing high arousal PA, which is more likely to tap into feelings of physical wellness. 


\section{REVIEW OF POSITIVE AFFECT AND HEALTH}

Below, is a brief assessment of the recent literature on PA and specific health outcomes, with a focus on studies from the last 15 years. Examples are drawn from high quality studies that account for critical factors in the study of PA and health, including adjusting for baseline health, health-relevant behaviors (e.g., smoking, exercise), disease relevant factors (e.g., medications, markers of disease progression), and NA or a similar negativity measure. Generally, recent studies have been consistent in considering these covariates, and PA results withstand adjustment for NA and other factors regularly (e.g., see meta-analysis by Chida \& Steptoe 2008).

\section{Mortality}

Longitudinal studies of PA that examine length of life in healthy populations are the most common type of study in this field (see reviews of this literature by Chida \& Steptoe 2008 and Diener \& Chan 2011 for examples of studies). Pressman and Cohen's review (2005) noted reliable PA benefits in studies of healthy older adults in approximately a dozen studies, but less consistency in middle aged and young populations. This PA benefit for older individuals is echoed by a recent meta-analysis (Zhang \& Han 2016) that revealed lower risk for mortality for those with high PA over age 55. There may be reasons to believe that PA matters more in the later parts of life than earlier, when other factors less related to PA are more closely predictive of death. For example, chronic illnesses are less likely to kill in early to mid life as compared to factors like unintentional injuries and homicides (Murphy et al. 2017) that may have nothing to do with PA. This type of issue may explain some inconsistencies in younger/middle aged groups (e.g., Liu et al 2016). Related to our previous discussion on arousal level, high arousal PA seems to be driving many of the PA-mortality effects in studies explicitly looking at this question (Petrie et al. 2018; Pressman \& Cohen 2012) raising the question of what it is about feeling excited and vigorous that is healthful.

\section{Morbidity}

Like studies of mortality, morbidity research is focused on measuring healthy populations at baseline who are followed prospectively over time. In this case, the outcome is whether PA is associated with future 
disease onset or incidence of injury. Although the diversity of morbidity outcomes (e.g., cardiovascular diseases, infection, physical decline) is impressive, the main limitation is a low replication rate within any one outcome type. The most studied literature in this category is work on cardiovascular outcomes. Specifically, there is extensive research in large, well-controlled epidemiological studies testing associations between self-reported PA and heart disease (see review by Boehm \& Kubzansky 2012). While there are a number of positive findings including PA benefits on outcomes like reduced stroke (Ostir et al. 2001) and decreased hospital readmission following cardiovascular issues (Middleton \& Byrd 1996), not all recent data is consistent. This is especially true for studies using assessments of PA that include a range of wellbeing measures that tap different positive constructs (e.g., optimism, confidence, life evaluations) via the CES-D and other similar measures (Freak-Poli et al. 2015). These mixed results point to a need for further replication and dissection of what specific types of positive measures help different cardiovascular relevant outcomes and when.

Beyond cardiovascular disease, some of the best evidence for PA's morbidity effects comes from the well-designed experimental cold and flu study paradigms. Typically, infectious illness studies are confounded by uncontrollable exposure-related issues. However, in experimental cold and flu study paradigms, all participants are exposed to a novel upper respiratory virus in isolation, with extensive health and demographic controls. Infection incidence is also assessed by objective indicators (e.g., mucus production, viral replication). In these studies, lower levels of state PA (over two weeks prior to exposure) have been tied to more objective and subjective signs of illness (Doyle et al. 2006). Furthermore, higher PA predicted resistance to both flu and cold, even after accounting for an array of related positive (optimism, extraversion, esteem, purpose), negative (NA), demographic, and health variables, replicating past similar work (Cohen et al. 2003).

There is evidence that PA is also predictive of future injury and the incidence of physical decline (i.e., slowed walking speed, weakened strength). For example, in two studies of older adults, higher PA (measured with the CES-D positive subscale) was associated with a reduced risk of frailty over a few years of follow-up (Park-Lee et al. 2009). Higher PA has also been associated with slower functional 
decline (e.g., inability to walk, self-feed, and bathe; Hirosaki et al. 2013) and lower likelihood of the development of a new disability (Diaz-Ramos et al. 2012) in older adults. This complements past work on younger samples tying PA and life satisfaction to a reduced risk of injury (Koivumaa-Honkanen et al. 2000; Smith et al. 1997), indicating a growing literature showing that PA is connected with better physical function across ages and domains.

\section{Disease Severity, Progression, and Survival in People with Chronic Illness}

At the time of past reviews on this literature, the evidence for PA benefits in those who are already ill was mixed, especially for survival, and little replication had been done at the disease level. The pattern seemed to indicate that individuals with early stage disease were better helped than those at later stages (see discussion in Pressman \& Cohen, 2005), possibly because the mechanisms (e.g., reduced stress, healthy behaviors) connecting PA to health have more room for impact before, for example, organs are failing and millions of cancer cells have replicated. This is echoed by a meta-analysis showing a very small effect of positive well-being on mortality in those with illness $(\mathrm{HR}=.98 ; \mathrm{CI}[.95,1.00] ; \mathrm{p}=.03$; Chida \& Steptoe 2008). At this point in the literature, there are mechanistic reasons by which most diseases described below could benefit from PA, and growing evidence to this end is described in the models section.

Cardiovascular disease. While not exclusively focused on PA, a recent systematic review revealed that many wellbeing constructs, including PA, are positively associated with lower cardiovascular disease severity (e.g., fewer cardiac events and rehospitalizations) and increased survival in patients with cardiovascular disease (Dubois et al. 2015), echoing above morbidity findings. In this review, six studies examined PA associations with survival. Benefits were found in studies using mid to high arousal scales (i.e., PANAS and a happiness scale; Grunberg et al. 2003; Hoen et al 2013) as opposed to studies using less pure assessments of PA like the Global Mood Scale (GMS; Denollet 1993). In one study, the GMS, which includes high arousal PA in addition to feelings of industry, sociability, and esteem, did predict survival. This effect was lost, however, after accounting for covariates including physical activity, which was hypothesized as a possible mediator of the survival effect (Hoogwegt et al. 2013). Evidence has also 
been found for PA predicting reduced cardiac events, even after adjusting for factors like disease severity and depression (e.g., Hoen et al. 2013, Hoogwegt et al. 2013). While high arousal PA seems to be helpful, given the potential negative effects of arousal on individuals with heart conditions, researchers will need to be wary of possible U-shaped associations in future studies (Armon et al. 2014). Despite mounting evidence that PA is related to better health outcomes in cardiovascular disease, it is clear that more work needs to be done to determine the types of PA that are most helpful in this context.

Diabetes. While a relatively new area, PA has also been tied to better survival in individuals with diabetes (Moskowitz et al. 2008). Of interest, when considering what drove this association, the item "I enjoyed life" in the CES-D PA subscale was most strongly predictive. Similarly, low PA (low scores on "I have looked forward with enjoyment to things," and "I have been able to laugh and see the funny side of things") was associated with an almost twofold increased risk of dying in patients with type 2 diabetes (Nefs et al. 2016). This is in line with studies associating higher PA with better glycemic control (Nefs et al. 2012), suggesting one likely mechanistic pathway in diabetes.

HIV. In patients diagnosed with HIV, positive feelings like compassionate love (Ironson et al. 2017) and other PA and PA-relevant measures (e.g., meaning, altruism) predict slower disease progression (Ironson \& Hayward 2008), a higher likelihood of achieving suppressed viral load (i.e., the treatment goal; Wilson et al. 2017), and higher survival (Moskowitz 2003). For example, a recently published longitudinal study indicated that PA assessed with the CES-D subscale was associated with a higher likelihood of subsequent viral load suppression in women with HIV (Wilson et al. 2017). While promising, because of the mix of PA-relevant constructs in this literature, it may be that a host of positive factors are helpful in managing a serious and multi-faceted illness like HIV.

Cancer. Surprisingly, there are few published studies of PA and recurrence, progression, or mortality among people with cancer. In a recent study of patients with metastatic renal cell carcinoma (Prinsloo et al. 2015), the PA subscale of the CES-D predicted longer survival. Notably, survival was better for patients who had both high PA and lower depressive symptoms, supporting the importance of looking at both valences together. This literature is still small and mixed (see Pressman \& Cohen 2005 for past 
examples), and many studies have been focused on understanding predictors of PA in cancer patients (e.g., Costanzo et al. 2009) rather than PA predicting cancer. That being said, there is extensive evidence for stress-related psychosocial factors predicting cancer incidence and poorer survival, with stressful events in particular playing an important role in survival (Chida et al. 2008). Given the stress-altering effects of PA (discussed below), there are many reasons to predict that PA could play an important role at multiple stages of disease.

\section{Self-Reported Symptoms and Pain}

PA has been consistently associated with reduced symptoms and pain ratings in both unhealthy and healthy samples. Recent studies have revealed that individuals who report higher PA report less pain in chronic pain conditions (Strand et al. 2007; Zautra et al. 2005), fewer symptoms during acute illness (Cohen et al. 2006; Doyle et al. 2006), and reduced pain months after being discharged from a hospital (Berges et al. 2011). Furthermore, benefits are also found in healthy samples (Kelsey et al. 2006). While a relatively consistent literature, there are some exceptions. For example, spinal surgery patients did not show a benefit of high arousal PA on pain months following surgery (Seebach et al. 2012), although PA did aid with physical function. Similarly, the high arousal GMS was not associated with post-angioplasty pain months later, although again, it was associated with better activity (e.g., self-care; Versteeg et al. 2009). This hints at the possibility that high arousal PA, in particular, may not be beneficial for pain, but is tied to physical function. Also of note is that there is some limit to examining self-reported data such as symptoms and pain in the context of PA given that there is no way of knowing if the effect is biological or perceptual. This is in addition to the problem of covariation between these variables based on the method of data collection (i.e., self-report) that could result in problems from self-presentation effects or other unintentional biases in reporting emotions and sensations.

\section{MODELS OF PA AND HEALTH}

It is evident that there are many connections between PA and health. The natural question that then arises is how is this happening? Researchers have hypothesized a number of plausible pathways that are only just starting to be investigated. Like the issues of measurement discussed above, it is essential for 
researchers to consider carefully theoretical, design, and statistical approaches to unraveling the likely complex mechanisms linking PA and health. Two promising models connected to this literature and evidence supporting them are reviewed below.

\section{The Main Effect Model of PA and Health}

The Main Effect Model of PA and health (Pressman \& Cohen 2005) is the common default model that researchers operate under when doing work in this area. It proposes that PA has main effects on health through pathways such as positive health behaviors; protective and/or health-relevant physiological changes; and social, psychological/intellectual, and physical resources. As shown in Figure 1, this model predicts that these types of factors mediate (paths a, b, c, and d) the association between PA and immune and cardiovascular systems which have implications for disease (path e). Many studies have supported the initial PA to posited mediator links (e.g., Figure 1 paths a and c). Each of these mediators is discussed below.

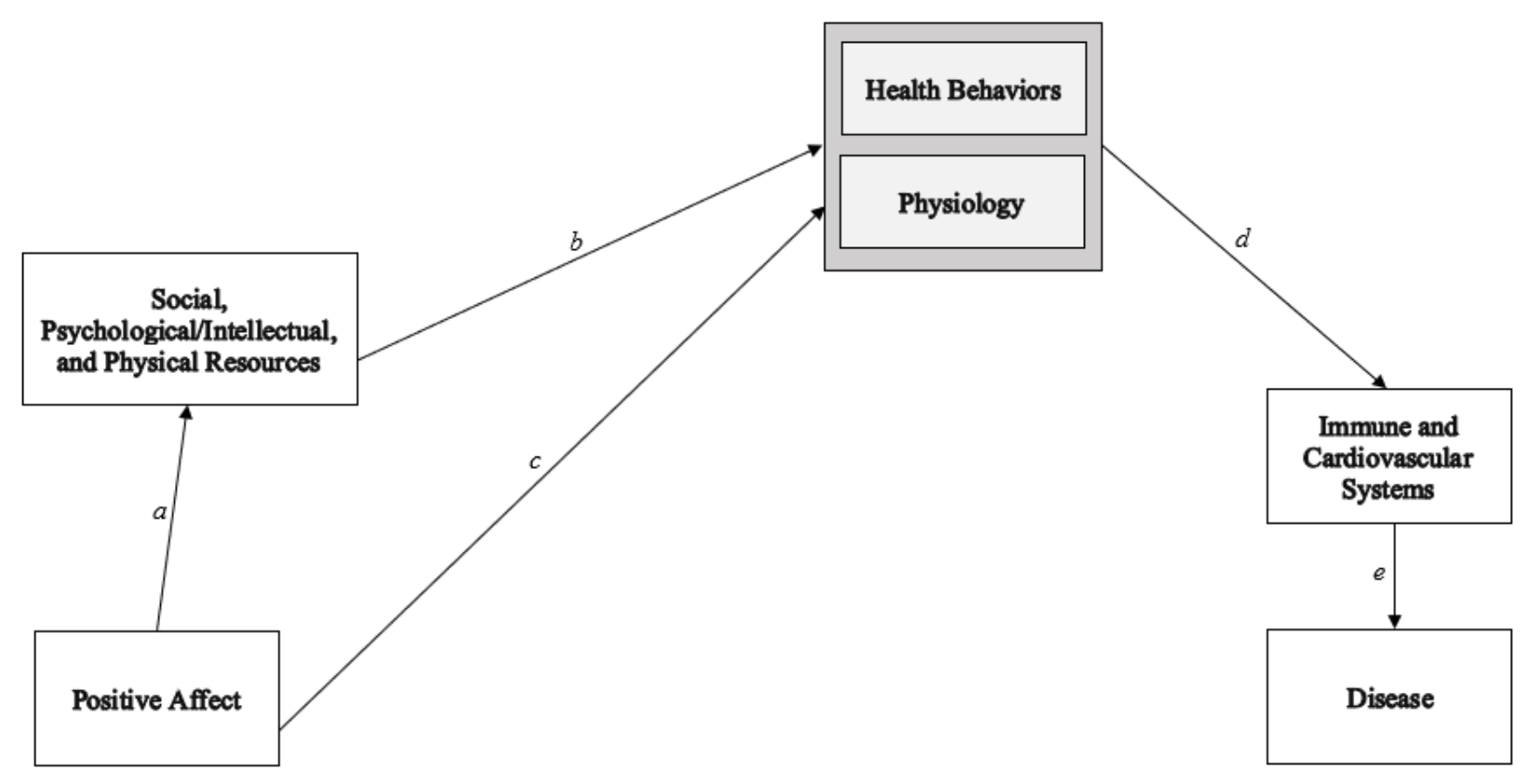

Figure 1. Main Effect Model of PA. This figure illustrates the mediating effect of resources (social, psychological/intellectual, and physical), health behaviors (e.g., sleep, diet, exercise), and physiology (e.g., hormones, microbiome, epigenetics, neurotransmitters, opioids) between PA and disease. An absence of a line does not indicate that an association between variables does not occur nor do arrows indicate a single direction of causality. Rather, lines drawn represent the focus of this model and arrows go in only one direction for simplicity. 


\section{Mediation.}

Health behaviors. Likely behavioral candidates for mediators of the PA and health association include physical activity (e.g., Hoogwegt et al. 2013; Kelsey et al. 2006), sleep (e.g., Ong et al. 2017b), and medication adherence (e.g., Ironson et al. 2017). Although few studies look at more than one health behavior in a single study, Whitehead (2016) tested the cross-sectional association between PA and a range of self-reported health behaviors (e.g., exercise, eating healthy, smoking, alcohol, sleep, flossing, seatbelt use), and found that only high arousal PA predicted better outcomes (specifically healthy eating and exercise) and that NA did not predict when PA was in the model.

Most of these studies are observational, but experimental evidence is beginning to accumulate, albeit with mixed results. Lab-based studies have shown that PA manipulations via film clips, music, emotional imagery, or memory evocation increased intentions to engage in physical activity (Cameron et al. 2015). PA manipulations also increase intentions to choose healthy food (Cameron et al. 2018). In clinical populations, PA inductions (e.g., via small gifts) and self-affirmation have been found to increase physical activity among coronary patients (Peterson et al. 2012) and to improve medication adherence in hypertensive populations (Ogedegbe et al. 2012). Activity findings did not replicate in asthmatics (Mancuso et al. 2012), however, and medication adherence effects were not found in a population of African Americans with hypertension (Boutin-Foster et al. 2016). Combining some of the self-affirmation studies above revealed that, on average, those participants who reported at least a one-standard-deviation decline in PA from baseline to 12 months were less likely to maintain their behavior change (Peterson et al. 2013).

Physiological functioning. Some of the most compelling and consistent evidence that PA could have a downstream health impact arises in the physiological biomarker literature. This research indicates that PA is associated with potentially health-benefiting differences in outcomes like immune function, stress

hormone levels, and cardiovascular function, including studies where PA is manipulated experimentally. For example, greater PA has been tied to healthier immune function, such as more robust vaccination responses, higher levels of circulating white blood cells, reduced inflammation, and faster healing (see 
review by Marsland et al. 2007). PA has also been associated with lower levels of the immune-altering hormone cortisol (e.g., Brummett et al. 2009; Steptoe et al. 2005); lower heart rate, blood pressure, and lipids (e.g., Blanchflower \& Oswald 2008, Steptoe et al. 2005); and healthier nighttime cardiovascular activity (i.e., low nocturnal heart rate and high heart rate variability; Bhattacharyya et al. 2008), a predictor of reduced mortality risk.

Some areas appear more mixed, however. For example, the fact that PA has been tied to both high stress-related sympathetic activity assessed via salivary alpha amylase (Nater et al. 2007) but also with higher relaxation-related parasympathetic nervous system function, assessed by heart rate variability (e.g., Bhattacharyya et al. 2008). Conflicting findings can be better understood by couching the interpretation of these findings in terms of the types of PA, context, and timing. Momentary high activation PA may be tied to brief sympathetic arousal, but in the context of stress, PA is associated with lower alpha amylase (Jenkins, et al. 2018b) and more stable PA is associated with lower sympathetic activity across the day (Doane \& Lenten 2014).

While most of this work relies on one-time self-report, converging evidence from other forms of PA assessment indicates that PA expression via smiling and positive word use is similarly associated with lower heart rate, blood pressure, and cholesterol (Davidson et al. 2010; Kraft \& Pressman 2012; Pressman \& Cohen, 2012). Another recent methodological advancement is work indicating that beyond PA or any specific type of PA, the diversity of felt emotions may also matter to physiological function, for example in immune function (Ong et al. 2017a). The area of PA and physiological pathways is impressive in its breadth, depth and replications, but one important next step will be to unpack the cyclical connections between emotion and physiology, for example in vagal activity (Kok and Fredrickson 2010; Thayer \& Lane 2000), to better understand to what extent some arrows in the described models are bi-directional, especially as new complex systems and pathways (e.g., microbiome, epigenetics, telomeres) are discovered and implicated in these findings.

Social, Psychological/Intellectual, and Physical Resources. Numerous reviews have detailed how social relationships are positively associated with healthier physiological functioning and better physical health 
(e.g., Kiecolt-Glaser et al. 2010), while isolation is harmful (Holt-Lunstad et al. 2015). Given the close association between social relationships and PA (Kok et al. 2013), it may be that variables such as felt support, social control, and integration operate as mediating pathways connecting PA to health.

In addition to social support variables, PA is also predictive of other resource accrual including coping resources (e.g., adaptive coping, resilience; Gloria \& Steinhardt 2016) and sociodemographic factors like higher education achievement, promotions, and financial success (Neve \& Oswald 2012). Since these psychological, intellectual, and physical resources impact physical health in their own right, they offer another distinct path through which PA predicts health.

\section{Testing the full model and conclusions.}

Although the majority of studies find support for the initial mediation link (i.e., Figure 1 paths $a$ and $c$ ) and between PA and physical health (the final outcome), only a few studies have tested the full mediation prediction of this model, with physical health as the dependent variable of interest. For example, Doyle et al. (2006) assessed baseline PA, experimentally exposed participants to a rhinovirus strain, and monitored

IL-6 (a marker of inflammation) and rhinovirus infection over the course of five days. They found that IL6 mediated the association between PA and infection severity. Similarly, Hoogwegt et al. (2013) found that physical activity moderated the association between PA and mortality during a five year follow up period.

One reason studies do not often test mediation may be related to the issue of timing. The predictions under this model span the course of several years, even decades, due to the amount of time it would take for these types of mechanisms to have a detectable impact on physical health, especially if starting with a young and healthy population. Furthermore, the mediators in this model do not represent single occurrences that can be measured at one point (e.g., it is unlikely that HPA activity over a single month in one's life would fully account for the association between PA and disease ${ }^{1}$ ). Thus, researchers may consider relying on existing longitudinal data sets that assessed mediators at multiple time points

\footnotetext{
${ }^{1}$ Although, if this one month was reflective of general HPA activity, this measure may partially account for PA-disease associations.
} 
throughout the lifespan and when designing studies, consider the issue of timing carefully when choosing assessment types, frequency, and interpretation.

\section{Stress Buffering Models of PA}

Pressman and Cohen (2005) also proposed the Stress Buffering Model of PA which hypothesizes that health benefits arise out of the ability of PA to reduce stress and its detrimental effects on the body. For example, PA may alter stress and coping appraisals, reduce stress reactivity (i.e., the degree of change in response to stress such as blood pressure increases), and/or hasten stress recovery. These stress alterations are beneficial, as both increased reactivity and prolonged recovery have detrimental long-term health effects (Fredrikson \& Matthews 1990). The Stress Buffering Model is consistent with the revised Stress and Coping Theory (Folkman 1997) and the Broaden and Build Theory of Positive Emotions (Fredrickson 1998, 2001). The Revised Stress and Coping Theory explicitly posits that PA provides a "time-out" from the distress associated with chronic stress and helps motivate and sustain ongoing efforts to cope. Broaden and Build explains that PA is evolutionarily adaptive in that it guides a person to explore and relax during safe and non-life-threatening times. These behaviors lead to the building of resources that can be called upon in other contexts even after the positive emotion state has passed and, in particular, during times of stress. At this point, PA is proposed to have an "undoing effect" that hastens recovery from stress. While few objective health outcome studies test this, there is growing evidence for its importance in outcomes like mortality (e.g., Mroczek et al. 2013).

The Stress Buffering Model has two broad predictions: one characterized by moderation and the second by mediation. First, PA moderates the link between stress and health behaviors/physiological functioning (Figure 2 path $c$ moderates path $f$; Figure 2 path $a$ leads to path $e$ which moderates path $f$ ) by weakening the stress-health behavior/physiology connection. Second, PA may reduce the occurrence of stress in and of itself (i.e., decreasing the likelihood of experiencing stress, reducing reactivity, speeding recovery from stress), thus leading to more desirable health behaviors/physiological functioning. In this prediction, stress mediates the association between PA and health-relevant variables either directly (i.e., Figure 2 paths $b$ and $f$ ) or indirectly by the resources accrued through PA (i.e., Figure 2 paths $a$, $d$, and $f$ ). 


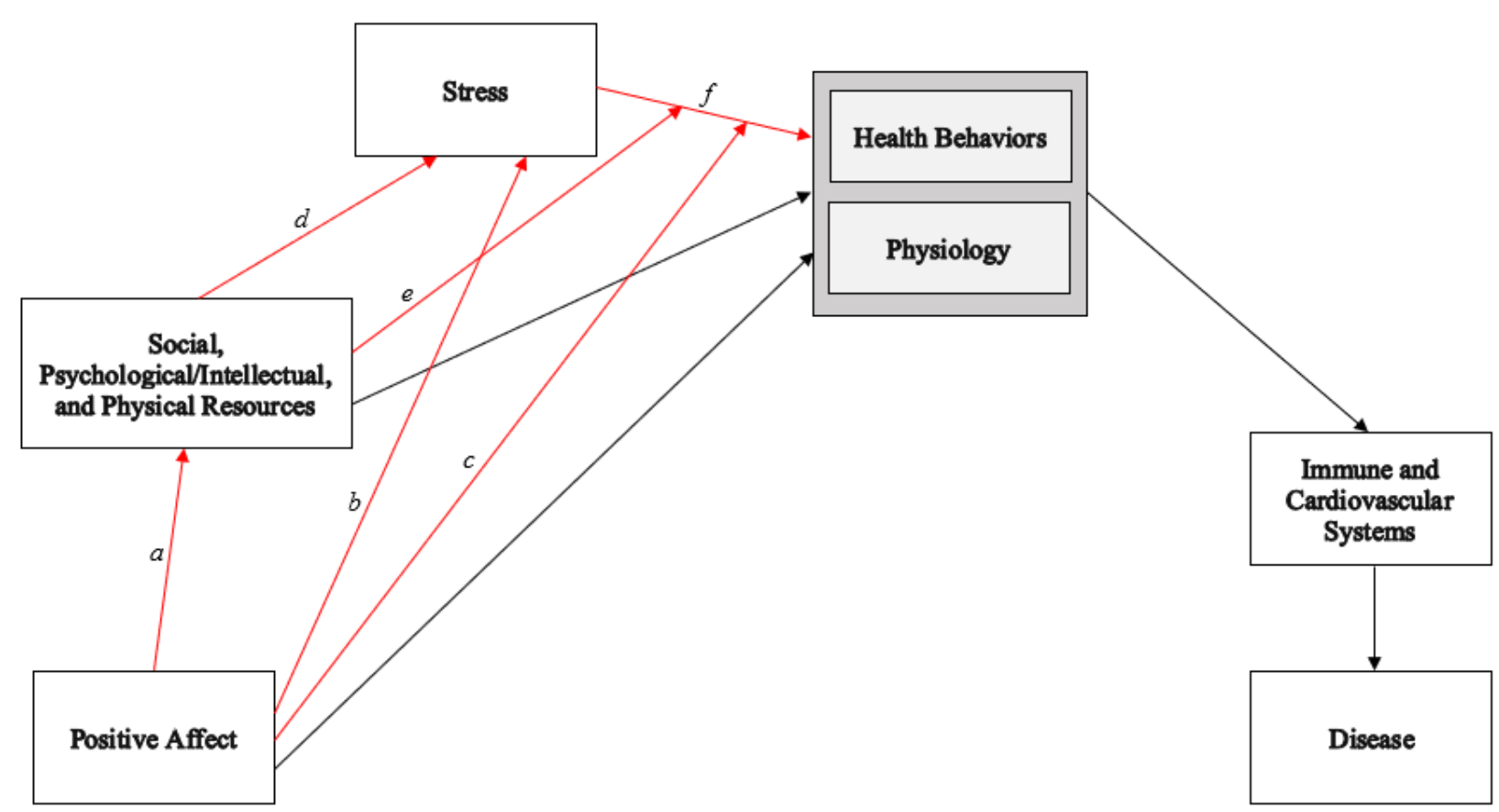

Figure 2. Adding the Stress Buffering Model to the Main Effect Model of PA. Red paths highlight paths added to the Main Effect Model (i.e., paths b through f) or those that were in the Main Effect Model but are also emphasized in the Stress Buffering Model (i.e., path a). An absence of a line does not indicate that an association between variables does not occur nor do arrows indicate a single direction of causality. Rather, lines drawn represent the focus of this model and arrows go in only one direction for simplicity.

Moderation. Testing moderation effects proposed here requires examination of the interaction term between PA and stress. Support of stress buffering is found in a significant interaction term whereby at high levels of stress, PA is even more health protective than it is at low levels of stress. In terms of design, there are four possible methods for testing this moderation effect: researchers can 1. use random assignment for both stress and PA, 2. can use random assignment for stress and measure naturally occurring PA, 3., use naturally occurring stress and randomly assign participants to receive a PA intervention, or 4. measure naturally occurring stress and PA. Without including a no (or low) stress condition, it is impossible to differentiate between the effects of PA on health at high versus low stress. Thus, studies in which there is only a stress condition (e.g., all participants assigned to a stress task or experiencing a naturally occurring stressor) are only testing part of the Stress Buffering Model.

To our knowledge, no study has randomized both stress and PA presence/absence/level. There are studies, on the other hand, that have manipulated either stress or PA. Stress is often experimentally 
induced through laboratory tasks (e.g., speech and pain tasks). For example, participants in an experimental wounding study were randomly assigned to give a speech or not (i.e., high vs. no stress), and naturally occurring trait PA was predictive of faster wound healing only in the stress group (Robles et al. 2009). In contrast, an example of random assignment to PA while measuring naturally occurring stress comes from Charlson et al. (2013) who found that individuals in a PA intervention who experienced naturally occurring stress over the study period had greater health behavior change as compared to participants in the control group. Finally, considering studies testing both naturally occurring stress and PA, Blevins and colleagues (2017) reported that PA moderates the link between stress and C-reactive protein levels (a marker of inflammation) such that at higher stress levels, higher PA is predictive of lower C-reactive protein. Surprisingly, high PA paired with high stress resulted in more favorable Creactive protein levels as compared to low stress regardless of PA, suggesting that at least in some cases high stress is associated with more favorable outcomes.

Mediation. PA likely not only moderates the effect of stress on health behaviors/physiology but also has a direct effect whereby it decreases stress (or makes it less likely that a person experiences stress), which then leads to more favorable outcomes. This process by which PA reduces stress is a test of mediation (Figure 2 paths $b$ and $f$; Figure 2 paths $a, d$, and $f$ ). Indeed, numerous studies find evidence that PA directly reduces self-reported stress (e.g., Bono et al. 2013). Investigators aiming to test this question of mediation should assess PA, stress, and health behaviors/physiological function to determine whether stress mediates the PA to health behaviors/physiological functioning link. Unfortunately, few studies have aimed to explicitly test this mediation; although, Charlson and colleagues (2013) found that increases in PA were associated with decreases in stress, which were eventually associated with increases in beneficial health behavior change in patients with chronic cardiopulmonary disease.

Conclusions. There are considerations that should be taken when testing the Stress Buffering Model (whether it be via moderation or mediation) or applying it in practical contexts. First, do positive emotions happen naturally during stress or do interventions need to be designed to increase PA during stressful experiences? Evidence for the former comes from Fredrickson and Levenson (1998) who found 
that almost $70 \%$ of their participants spontaneously smiled during negative stimuli (which aided cardiovascular recovery). However, if positive emotions need to be induced during times of stress, careful consideration should be made with regard to context and methods of induction. For example, immediately following cancer diagnosis it may be inappropriate to engage in certain PA interventions. In contrast, during a brief painful procedure (e.g., flu shot), this same method may be quite helpful. Second, it is important to identify a priori whether variables are mediators, moderators, or outcome variables. When testing the Stress Buffering Model, health behaviors and physiological functioning may be outcome variables of interest but may also be mediators that lead to changes in immune and cardiovascular system functioning.

\section{Future Directions in Models}

The majority of the PA and health literature and theories focus on broad PA assessments. However, there is value in examining the differential effects of PA subtypes and how this factors into the specifics of the disease biology or stress context. As shown above, high arousal PA may be beneficial in some health outcomes (e.g., mortality) but harmful in other physiological processes when arousal can be damaging (e.g., pain). This may also be true for stress. For example, during times of average to low stress, low arousal PA is most beneficial for helping students get good sleep, but during very high exam stress that requires active coping, trait high arousal PA is most helpful (Pressman et al. 2017). Therefore, PA might work best when the arousal level of PA matches the needs of the individual, the context, and, when relevant, the specific stressor. For example, during times of stress when an active coping style is necessary, high arousal PA may provide an individual with the necessary energy to engage in active coping. Although most studies do not take arousal level into account, there is clearly evidence that health findings differ based on positive arousal, as well as evidence that high arousal PA is beneficial during active stress (Brooks 2013).

\section{DOES INTERVENING ON PA IMPROVE HEALTH?}

Spurred by the growing evidence that PA uniquely predicts health outcomes, there is great interest in designing positive psychology interventions that will benefit health. The guiding hypothesis for this work 
is that the interventions will increase PA which will then, via the paths described above (e.g., health behavior change, stress reduction), improve physical health. This literature is new, with few studies to date focusing on physical health outcomes. Thus, below is a summary of promising PA-relevant intervention effects in samples with chronic illness. Also highlighted are real world, applied, interventions meant to have enduring effects on PA (and health) as opposed to studies of transient emotion induction in the lab (known to alter physiology in the moment but unlikely to have long term health effects).

Most published interventions in people living with chronic illness utilize a multi-component approach (i.e., they teach a range of positive skills rather than focusing on a single activity type). This "buffet" style intervention makes sense, given that there is not enough data at this point to pick a targeted manipulation type and there is evidence that individuals like having more than one choice of activity (Schueller \& Parks 2012). Intervention activities arise primarily out of research in positive psychology known to increase PA and related positive factors. They focus on topics such as engaging in acts of kindness, practicing gratitude, trying to extend positive events by savoring them, practicing personal strengths, imagining best possible selves, thinking optimistically, and engaging in different forms of mindfulness. Together, these activities have been repeatedly shown to improve psychological well-being (including PA) and decrease depressive symptoms, with small effect sizes in the general public as well as in individuals with mental health concerns ( $r$ s in the $.2-.35$ range; e.g., Bolier et al. 2013). Thus, there is good reason to think that in populations with chronic illness, benefits could occur as well, helping these individuals cope with the adverse negative experiences of a major life threat and, perhaps, improve their psychological and physical wellbeing.

The growing field of PA intervention studies in ill populations, while impressive in breadth, have a range of quality levels. For example, few studies have sufficient sample size, strong control conditions, diverse samples, and the high retention rate required for definitive conclusions. However, even with these interpretative limits in mind, there is promising work showing that PA can be increased in a wide range of ill samples such as those with heart disease (Huffman et al. 2016), diabetes (although only for those recruited online; Cohn et al. 2014), early stage cancer (see review by Casellas-Grau et al. 2014), 
and newly diagnosed HIV (Moskowitz et al. 2017), with some studies showing PA benefits remaining over a year later. Studies in patients with advanced cancer have fewer significant effects on PA, although the sample sizes are generally small, so researchers should not over-interpret these findings (e.g., Cheung et al. 2017).

While the PA intervention literature is promising, little work has found objective health-altering effects and PA has not yet been demonstrated as a mediator between intervention and health. Still, early evidence indicates small to moderate effect sizes of a PA skill training intervention on viral load suppression and reduced needs for opioid analgesics in people living with HIV (Addington et al. 2018; Moskowitz et al. 2017), and real-world PA interventions have been tied to elevated vagal tone, a marker of physiological relaxation and heart health (Kok \& Fredrickson 2010). Studies of individuals living with hypertension have not found benefits from self-affirmation (Boutin-Foster et al. 2016; Ogedegbe et al. 2012), however, in a healthy population, a brief prosocial spending intervention led to reduced blood pressure (Whillans et al. 2016). Clearly it is too early to determine whether and when PA interventions will have benefit for those living with chronic illness. The field has barely begun to answer questions like which delivery format is most effective (e.g., online, in person, by phone), how many sessions are needed, and which components (e.g., gratitude, acts of kindness, savoring) have the greatest impact, all critical questions that need exploration.

As researchers move forward on these questions, it will be important to start with a theoretical framework that guides the selection of intervention components and PA measurement targets, as well as careful consideration of what mechanisms might be most relevant. For example, if cardiovascular disease is the outcome, physical activity is one likely mechanism connecting PA to better heart function. Thus it might behoove researchers to focus on higher activation types of PA that predict physical activity (e.g., Hoogwegt et al. 2013) and on interventions that impact that type of PA. Complicating this approach is the fact that most positive interventions increase a range of positive constructs (e.g., PA but also life satisfaction, optimism, hope, happiness; Mohammadi et al. in press), as well as decreasing negative outcomes (e.g., intrusive and avoidant thoughts, use of mood altering drugs; e.g., Moskowitz et al. 2017). 
This makes a targeted approach more difficult (since it is hard to pinpoint the "active ingredient") but also interventions potentially more efficacious if the psychobehavioral outcomes work together to promote health in a similar direction. In addition, a guiding framework emphasizing basic science during intervention development will increase the likelihood that health-related interventions are maximally effective and successfully implemented in applied clinical settings. Furthermore, a systematic approach where factors like disease stage and the specific psychological needs at that stage will result in stronger evidence to optimally tailor interventions to the disease course. This could contribute to more options for conducting interventions that go beyond a focus on individual behaviors, potentially to larger systemslevel interventions that can have a much broader impact on public health.

\section{FUTURE DIRECTIONS FOR DESIGN, METHODOLOGY, AND STATISTICAL PRACTICES}

As researchers move forward in the study of PA and health, there are many additional issues to consider beyond what has been discussed above. Central issues include exploring covariates, mediators, and moderators; considering other statistical methods; dealing with other positive constructs; and utilizing new technology in the field.

\section{Covariates, Mediators, and Moderators}

Careful consideration should be given to which variables are treated as covariates, mediators, and moderators. For example, sociodemographic variables might be possible covariates or, alternatively, play important roles as moderators. Pressman \& Cross (in press) outlined how cultural differences in the emotions individuals idealize (Tsai 2007) may alter whether certain types of PA are beneficial to health. If a desired state is low arousal, but an individual feels high in arousal, will it be helpful or harmful? This question remains unanswered, but ideal affect is starting to be investigated in the context of medical outcomes (Sims et al. 2014). Related to this, geographic location (e.g., country) may also play a role in the PA-health relation, as evidenced by a study indicating that the PA-health association is more robust in poorer countries, even after accounting for NA and basic needs (Pressman et al. 2013). This may be due to the ability of advanced medical technology and resources to ameliorate some of the negative effects of affect variables in more affluent countries. Finally, it is critical that age be more regularly treated as a 
moderator. As evidenced by the mortality data, PA matters more for health in later stages of life when chronic disease processes are more in play and PA has the ability to alter mechanisms that lead to changes in these processes. Complicating this line of research are the changes in PA as individuals age, such as an increase in positivity, but also a preference for lower arousal (Charles \& Carstensen 2010). What does this mean for the high arousal PA findings on mortality? Is high arousal PA beneficial in these older samples because it is less common and only found in the healthiest aged adults? More research on this, especially research carefully disentangling the interconnections between age, health, and affect, is needed.

Given that any effect of PA may be partially or fully explained by an absence of NA, it has been long advocated that NA or related negative constructs should be adjusted for in PA-health models (e.g., Chida \& Steptoe 2008; Pressman \& Cohen 2005). Most, but not all, of the studies reviewed here include some negative measure as a covariate. Since many PA measures are highly correlated with NA (Diener \& Emmons 1984), including them in the same model can be difficult, leading many researchers to control for depression or anxiety measures instead (e.g., Lambiase et al. 2015). This results in analyses controlling for symptoms that travel with depression or anxiety such as difficulties with concentration, self-injury, eating, and sleep (Kroenke et al. 2001; Radloff 1977). The approach of using clinical tools rather than NA results in interpretative differences in the meaning of the adjustment. Thus, researchers should be specific about the meaning of the negative construct that is covaried, honest regarding its limitations, and open to utilizing other methods. For examples, research could report the effects of both NA and PA or utilize affect balance or ratio approaches to see whether NA and PA factored together have better explanatory power. While ratio research has been controversial (i.e., the "critical positivity ratio of 3:1"; Brown et al. 2013, Fredrickson \& Losada 2005) and affect balance results mixed, these statistical approaches can provide information on whether it is beneficial to have more PA relative to NA. They cannot, however, indicate if one variable is more important than the other and/or say anything about active subcomponents. To date, there is little data on the health value of ratios (see Steinhardt et al. 2015 for one example in type 2 diabetics) and affect balance (e.g., Hassett et al. 2008), but such work can help inform whether interventions should target increasing PA, decreasing NA, or both. 


\section{Statistical and Design Considerations}

Though rarely discussed, it is important to consider that the association between PA and health may not be linear; for example, studies have revealed that a medium amount of high arousal PA is best for cardiovascular outcomes (Armon et al. 2014). Relatedly, new work in the area of PA and health is moving beyond modeling average levels of PA by exploring PA variability, PA reactivity, and patterning of PA. For example, higher PA variability is associated with poorer self-reported physical health and a greater likelihood of illness diagnosis (Chan et al. 2016). Similarly, larger PA reactivity to stress (i.e., larger drops in PA resulting from daily stressors) on a day to day basis has been associated with increased mortality 10 years later, even when assessed over just a few days (Mroczek et al. 2013). In contrast, individuals who experience increasing PA over the course of the day have the lowest risk of current and future coronary artery calcification (Kroenke et al. 2012). Mroczek and colleagues (2006) argued that one possible reason for some health detriments of variability and reactivity is that this rapid change in emotion may over engage certain physiological stress pathways, much in the same way that stress reactivity has been argued to have downstream health effects. It might also change negative health behaviors, but generally, the mechanisms underlying why frequent ups and downs in affect might be harmful are unstudied. It is also beneficial to consider interactions between variability and mean levels of PA, with implications for health (e.g., Jenkins et al. 2018a; Ong \& Ram 2017). Further, novel approaches may be needed to deal with the possibility that certain types of patterning of PA (e.g., patterns of change that repeat) may matter (Jenkins 2017). Thus, it is clear that advanced statistical approaches have begun to increase our understanding of the dynamics of PA and their relation to health but more work in this area is needed to know when and how these associations occur.

As alluded to earlier, issues of reverse causality arise often in this line of research, especially when there is conceptual or item overlap between the PA and health measure. Resources, health behaviors, and physiological functioning may all be variables that lead to changes in PA. Therefore, in relation to study design, it is important to accumulate prospective or experimental data in which PA is assessed or induced before changes in these variables and that health is carefully controlled in multiple 
ways (e.g., self-report, objective) at baseline so that confidence that it is truly PA predicting health can be bolstered.

To date, emotion-health research has mostly evaded discussion of the replication crisis and other growing methodological concerns (e.g., Maxwell et al. 2015), possibly due to the high cost of work in this field (e.g., large longitudinal samples requiring decades of follow up, expensive biomarkers). For this reason, PA-health researchers must be especially vigilant to ensure that studies are high quality. Bayesian frameworks, in which traditional hypothesis testing is set aside in favor of estimating coefficient distributions, should be considered, as should studies that preregister hypotheses and covariate selection to reduce the likelihood of atheoretical fishing expeditions. While it is easy for the media to sensationalize a single finding on happiness predicting health, researchers must be persistent in conceptually or directly replicating findings to test the robustness and generalizability of the connections found.

\section{Dealing with Other Positive Constructs}

While correlated, PA is distinct from other measures of wellbeing like life purpose, life satisfaction, and optimism, which are sometimes described as more conscious and cognitive judgements and can be focused on different time assessments (e.g., expectations for the future). While it is clear that many of these measures have robust associations with health as well, the mechanisms by which these measures influence health may be different. To add complication, in some cases, PA is a pathway by which these other positive variables influence important outcomes such as immunity and airway function (e.g., Crittenden et al. 2014; Segerstrom \& Sephton 2010); yet, in other cases, PA operates as a moderator (Nater et al. 2010). Therefore, what is also needed is a broader theoretical model examining how the widely studied range of positive constructs in health research (Cross et al. 2018) fit and work together to foster health in different contexts. Do they have unique paths? Are certain components helpful at certain time points of disease or for certain types of disease? Do many operate via similar mechanisms, for example, do trait and eudaimonic measures influence health via their influence on day to day and state PA? Careful consideration will need to be taken given the high degree of statistical overlap between some 
of these factors; thus, like with NA, researchers must carefully consider how to deal with these factors from a theory-based perspective.

\section{New Technology}

As in many areas of psychology and medicine, exciting technological developments will enable breakthroughs in this field. Wearable biosensing devices will advance our knowledge of how varying emotion in the real world translates into changes in behavior and physiology on a moment-to-moment basis. Newer, better, and easier mobile data collection platforms will encourage real-time and real-world approaches that address critiques and biases of one-time in-lab approaches and enable better assessments of affect variability. Finally, big data sets available through the push for open science, growing electronic hospital records, social media, and companies assessing large amounts of genetic and microbiome data will certainly lead to new discoveries, as will machine learning approaches to analyzing and synthesizing these massive amounts of data.

\section{CONCLUSIONS}

Positive psychology comes under regular attack from critics, perhaps due to cynicism regarding the idea that something as "fluffy" seeming could have real health effects, confusing societal attitudes about happiness with empirical findings, or the endless list of happiness self-help books published by nonresearchers. With this in mind, the PA-health literature has faced attacks on the value of positivity for health (e.g., Nickerson et al. 2018). Nevertheless, these claims have been well defended (e.g., Fredrickson \& Kok 2018) and earlier findings have been replicated and extended (e.g., Fredrickson et al. 2015; Isgett et al. 2017). One possible reason for this focused criticism is the belief about the "tyranny of positive attitude" (Held 2002), but by no means does health research, or positive psychology for that matter, ignore or dismiss the role of negative emotions. To find evidence that positive factors have a unique role in health, researchers often work all the harder to demonstrate that PA effects are unique and not simply the opposite of NA. Meanwhile researchers in depression, hostility, and anger are not expected to do the same with regard to PA. Moreover, it has also been previously suggested by PA-health researchers that too much positivity might be harmful in some circumstances. For example, high activity positive 
emotions might be harmful to conditions exacerbated by arousal (e.g., asthma, irritable bowel) or in end stage diseases where positivity may lead to earlier death. For the latter, it may be that high PA in the face of threat could decrease the likelihood of care seeking behavior or reduce vigilance about symptoms (see discussion in Pressman \& Cohen 2005). Manic PA can also be harmful in numerous circumstances (see discussion in Diener \& Chan 2011). Thus, there is already serious consideration toward a balanced approach to how and when PA is helpful versus harmful, and how this plays out in concert with NA (such as work on ratios and affect balance).

Together, this research area is compelling and promising. While early in terms of the intervention research building health, the cross sectional and longitudinal data showing connections between PA and disease or mortality relevant outcomes is difficult to ignore. There are still important gaps in the literature. There is a need for thoughtfully picked PA measurement tools partnered with health outcomes and plausible mediators in a single study. There are also missing types of studies, such as designs manipulating both stress and PA. That said, in the larger body of evidence showing a broad array of probable physiological, social, and behavioral connectors, it seems like only a matter of time before all the pieces come together. Thus, there is reason to be optimistic about this literature and its future. That said, given the widespread public and media interest in this topic researchers must monitor themselves carefully. Given the myriad of ways that PA can be operationalized and the complexity of health pathways and outcomes, no single study can provide THE ANSWER to the question of whether PA reliably predicts a healthier or longer life. Well designed and well controlled studies are expensive and time consuming, as evidenced by all the important methodological issues discussed above; thus, each study should be considered as a valuable and necessary way to complete the larger puzzle. Researchers must also begin to investigate how this work can be used to improve the health of the populace in order to draw public policy makers' and funders' attention. Only with this approach can researchers hope to convince doctors, public health experts, and policy makers that PA-health work is uniquely valuable and that it has the potential to help people live longer, healthier, and higher quality lives. 


\section{Literature Cited}

Addington EL, Cheung EO, Moskowitz JT. 2018. Positive affect skills may improve pain management in people with HIV. J. of Heal. Psychol.

Armon G, Melamed S, Berliner S, Shapira I. 2014. High arousal and low arousal work-related positive affect and basal cardiovascular activity. J. of Pos. Psychol. 9(2): 146-154.

Berges IM, Seale G, Ostir GV. 2011. Positive affect and pain ratings in persons with stroke. Rehab. Psychol. 56(1): 52.

Bhattacharyya M, Whitehead D, Rakhit R, Steptoe A. 2008. Depressed mood, positive affect, and heart rate variability in patients with suspected coronary artery disease. Am. Psychosom. Soc. 1027: $1020-1027$.

Blanchflower DG, Oswald AJ. 2008. Hypertension and happiness across nations. J. Health Econ. 27(2): 218-233.

Blevins CL, Sagui SJ, Bennett JM. 2017. Inflammation and positive affect: examining the stressbuffering hypothesis with data from the national longitudinal study of adolescent to adult health. Brain. Behav. Immun. 61: 21-26.

Boehm JK, Kubzansky LD. 2012. The heart's content: the association between positive psychological well-being and cardiovascular health. Psychol. Bul. 138(4): 655-691.

Bolier L, Haverman M, Westerhof GJ, Riper H, Smit F, Bohlmeijer E. 2013. Positive psychology interventions: a meta-analysis of randomized controlled studies. BMC Public Health 13(1): 119.

Bono JE, Glomb TM, Koch AJ. 2013. Building positive resources: effects of positive events and positive reflection on work stress and health. Georgia Institute of Technology. 56(6): 16011627.

Boutin-Foster C, Offidani E, Kanna B, Ogedegbe G, Ravenell J et al. 2016. Results from the trial using motivational interviewing, positive affect, and self-affirmation in African Americans with hypertension (TRIUMPH). Ethn. Dis. 26(1): 51-60. 
Brooks AW. 2013. Get excited: reappraising pre-performance anxiety as excitement. J. Exp. Psychol. Gen. 143: 1-15.

Brown NJL, Sokal AD, Friedman HL. 2013. The complex dynamics of wishful thinking: the critical positivity ratio. Am. Psychol. 68(9): 801-813.

Brummett BH, Boyle SH, Kuhn CM, Siegler IC, Williams RB. 2009. Positive affect is associated with cardiovascular reactivity, norepinephrine level, and morning rise in salivary cortisol. Psychophysiology 46(4): 862-869.

Cameron DS, Bertenshaw EJ, Sheeran P. 2015. The impact of positive affect on health cognitions and behaviours: a meta-analysis of the experimental evidence. Health Psychol. Rev. 9(3): 345365.

Cameron DS, Bertenshaw EJ, Sheeran P. 2018. Positive affect and physical activity: testing effects on goal setting, activation, prioritisation, and attainment. Psychol. Heal. 33(2): 258-274.

Casellas-Grau A, Font A, Vives J. 2014. Positive psychology interventions in breast cancer: A systematic review. Psychooncology. 23(1): 9-19.

Chan DKC, Zhang X, Fung HH, Hagger MS. 2016. Affect, affective variability, and physical health: results from a population-based investigation in China. Int. J. Behav. Med. 23(4): 438-446.

Charles ST, Carstensen LL. 2010. Social and emotional aging. Ann. Rev. of Psychol. 61: 383-409.

Charlson ME, Wells MT, Peterson JC, Boutin-foster C, Ogedegbe GO et al. 2013. Mediators and moderators of behavior change in patients with chronic cardiopulmonary disease: the impact of positive affect and self-affirmation. Transl. Behav. Med. 4(1): 7-17.

Cheung EO, Cohn MA, Dunn LB, Melisko ME, Morgan S et al. 2017. A randomized pilot trial of a positive affect skill intervention (lessons in linking affect and coping) for women with metastatic breast cancer. Psycho-oncology. 26(12): 2101-2108.

Chida Y, Hamer M, Wardle J, Steptoe A. 2008. Do stress-related psychosocial factors contribute to cancer incidence and survival?. Nature Reviews Clin. Oncology 5(8): 466-475. 
Chida Y, Steptoe A. 2008. Positive psychological well-being and mortality: a quantitative review of prospective observational studies. Psychosom. Medicine 70(7): 741-756.

Cohen S, Alper CM, Doyle WJ, Treanor JJ, Turner RB. 2006. Positive emotional style predicts resistance to illness after experimental exposure to rhinovirus or influenza a virus. Psychosom Med 68(6): 809-815.

Cohen S, Doyle WJ, Turner RB, Alper CM, Skoner DP. 2003. Emotional style and susceptibility to the common cold. Psychosom. Med. 65(4): 652-657.

Cohn MA, Pietrucha ME, Saslow LR, Hult JR, Moskowitz, JT. 2014. An online positive affect skills intervention reduces depression in adults with type 2 diabetes. J. of Pos. Psychol. 9(6):523534.

Costanzo ES, Ryff CD, Singer BH. 2009. Psychosocial adjustment among cancer survivors: findings from a national survey of health and well-being. Heal Psychol. 28(2): 147.

Crittenden CN, Pressman SD, Cohen S, Janicki-Deverts D, Smith BW, Seeman TE. 2014. Social integration and pulmonary function in the elderly. Health Psychol. 33(6): 535-543.

Cross MP, Hofschneider L, Grimm M, Pressman SD. 2018. Subjective well-being and physical health. In Diener E, Oishi S, Tay L. Eds. Noba Textbook Series: Psychology. Champaign, IL: DEF Publishers.

Davidson KW, Mostofsky E, Whang W. 2010. Don’t worry, be happy: positive affect and reduced 10-year incident coronary heart disease: the Canadian Nova Scotia health survey. Eur Hear. J 31(9): 1065-1070.

Denollet J. 1993. Emotional distress and fatigue in coronary heart disease: The Global Mood Scale (GMS). Psychol. Med. 23(1): 111-121.

Díaz-Ramos JA, Navarrete-Reyes AP, Ávila-Funes J.A. 2012. Positive affect in elderly Mexicans and its protective role against disability. J. of the Am. Geriatrics Soc. 60(2): 384-385.

Diener E, Chan MY. 2011. Happy people live longer: subjective well-being contributes to health and longevity. Appl. Psychol. Heal. Well-Being 3(1): 1-43. 
Diener E, Emmons RA. 1984. The independence of positive and negative affect. J. Personal. Soc. Psychol. 47(5): 1105-1117.

Doane LD, Van Lenten SA. 2014. Multiple time courses of salivary alpha-amylase and dimensions of affect in adolescence. Psychoneuroendocrinology 49(1): 47-53.

Doyle WJ, Gentile DA, Cohen S. 2006. Emotional style, nasal cytokines, and illness expression after experimental rhinovirus exposure. Brain Behav. Immun. 20(2): 175-181.

DuBois CM, Lopez OV, Beale EE, Healy BC, Boehm JK, Huffman JC. 2015. Relationships between positive psychological constructs and health outcomes in patients with cardiovascular disease: a systematic review. Int. J. of Cardiol. 195: 265-280.

Dufner M, Brümmer M, Chung JM, Drewke PM, Blaison C, Schmukle SC. 2017. Does smile intensity in photographs really predict longevity? A replication and extension of Abel and Kruger (2010). Psychological Sci.

Eichstaedt JC, Schwartz HA, Kern ML, Park G, Labarthe DR et al. 2015. Psychological language on Twitter predicts county-level heart disease mortality. Psychol. Sci. 26(2): 159-169.

Ekman P, Davidson RJ. 1993. Voluntary smiling changes regional brain activity. Psychol. Sci. 4(5): $342-345$.

Folkman S. 1997. Positive psychological states and coping with severe stress. Soc. Sci. Med. 45: $1207-1221$.

Freak-Poli R, Mirza SS, Franco OH, Ikram MA, Hofman A, Tiemeier H. 2015. Positive affect is not associated with incidence of cardiovascular disease: a population-based study of older persons. Preventive Med. 74: 14-20.

Fredrickson BL. 2001. The role of positive emotions in positive psychology. The broaden-and-build theory of positive emotions. Am. Psychol. 56(3): 218-226.

Fredrickson BL, Grewen KM, Algoe SB, Firestine AM, Arevalo JMG et al. 2015. Psychological well-being and the human conserved transcriptional response to adversity. PLoS One 10(3): $11-17$. 
Fredrickson BL, Kok BE. 2018. Evidence for the upward spiral stands steady: a response to Nickerson (2018). Psychol. Sci. 29(3): 467-470.

Fredrickson BL, Levenson RW. 1998. Positive emotions speed recovery from the cardiovascular sequelae of negative emotions. Cogn. Emot. 12(2): 191-220.

Fredrickson BL, Losada MF. 2005. Positive affect and the complex dynamics of human flourishing. Am. Psychol. 60(7): 678-686.

Fredrikson M, Matthews KA 1990. Cardiovascular responses to behavioral stress and hypertension: a meta-analytic review. An. Beh. Med. 12(1), 30-29.

Friedman EM, Ruini C, Foy R, Jaros L, Sampson H, Ryff CD 2017. Lighten UP! A communitybased group intervention to promote psychological well-being in older adults. Aging Ment. Health 21(2): 199-205.

Gloria CT, Steinhardt MA. 2016. Relationships among positive emotions, coping, resilience and mental health. Stress Heal. 32(2): 145-156.

Grad FP. 2002. The preamble of the constitution of the World Health Organization. Bul. of the World Health Org. 80(12): 981-981.

Grunberg GE, Crater SW, Green CL, Seskevich J, Lane JD et al. 2003. Correlations between preprocedure mood and clinical outcome in patients undergoing coronary angioplasty. Cardiology in Rev. 11(6): 309-317.

Hassett AL, Simonelli LE, Radvanski DC, Buyske S, Savage S V, Sigal LH. 2008. The relationship between affect balance style and clinical outcomes in fibromyalgia. Arthritis Rheum. 59(6): $833-840$.

Held BS. 2002. The tyranny of the positive attitude in America: observation and speculation. J. of Clin. Psychol. 58(9): 965-991.

Hernandez R, Bassett SM, Boughton SW, Schuette SA, Shiu EW, Moskowitz JT. 2018. Psychological well-being and physical health: associations, mechanisms, and future directions. Emotion 10(1): 18-29. 
Hirosaki M, Ishimoto Y, Kasahara Y, Konno A, Kimura Y et al. 2013. Positive affect as a predictor of lower risk of functional decline in community-dwelling elderly in Japan. Geriatr. Gerontol. Int. 13:1051-8.

Hoen PW, Denollet J, De Jonge P, Whooley MA. 2013. Positive affect and survival in patients with stable coronary heart disease: findings from the Heart and Soul Study. J. Clin. Psychiatry 74(7): 716-22.

Holt-Lunstad J, Smith TB, Baker M, Harris T, Stephenson D. 2015. Loneliness and social isolation as risk factors for mortality. Perspect. Psychol. Sci. 10(2): 227-237.

Hoogwegt MT, Versteeg H, Hansen TB, Thygesen LC, Pedersen SS, Zwisler A-D. 2013. Exercise mediates the association between positive affect and 5-year mortality in patients with ischemic heart disease. Circ. Cardiovasc. Qual. Outcomes 6(5): 559-566.

Huffman JC, Dubois CM, Mastromauro CA, Moore S V., Suarez L, Park ER. 2016. Positive psychological states and health behaviors in acute coronary syndrome patients: A qualitative study. J. Health Psychol. 21(6): 1026-1036.

Ironson GH, Hayward HS. 2008. Do positive psychosocial factors predict disease progression in HIV-1? A review of the evidence. Psychosom. Medicine. 70(5):546.

Ironson GH, Kremer H, Lucette A. 2017. Compassionate love predicts long-term survival among people living with HIV followed for up to 17 years. J. Posit. Psychol. 1-10.

Isgett SF, Kok BE, Baczkowski BM, Algoe SB, Grewen KM, Fredrickson BL. 2017. Influences of oxytocin and respiratory sinus arrhythmia on emotions and social behavior in daily life. Emotion 17(8): 1156-1165.

Jenkins BN. 2017. Affect variability is constantly important: implications for health. doctoral dissertation. University of California, Irvine.

Jenkins BN, Granger DA, Roemer R, Martinez A, Torres T, Fortier MA. 2018b. Emotion regulation and positive affect in the context of salivary alpha amylase response to pain in children with cancer. Ped Blood \& Cancer, e26973. 
Jenkins BN, Hunter JF, Cross MP, Acevedo AM, Pressman SD. 2018a. When is affect variability bad for health? The association between affect variability and immune response to the influenza vaccination. J. Psychosom. Res. 104(May 2017): 41-47.

Kelsey KS, DeVellis BME, Begum M, Belton L, Hooten EG, Campbell MK. 2006. Positive affect, exercise and self-reported health in blue-collar women. Am. J. Health Behav. 30(2): 199-207.

Kiecolt-Glaser JK, Gouin JP, Hantsoo L. 2010. Close relationships, inflammation, and health. Neurosci. Biobehav. Rev. 35(1): 33-38.

Koivumaa-Honkanen H, Honkanen R, Viinamäki H, Heikkilä K, Kaprio J, Koskenvuo, M. 2000. Self-reported life satisfaction and 20-year mortality in healthy Finnish adults. Am. J. of Epidemiology. 152(10): 983-991.

Kok BE, Coffey KA, Cohn MA, Catalino LI, Vacharkulksemsuk T et al. 2013. How positive emotions build physical health: perceived positive social connections account for the upward spiral between positive emotions and vagal tone. Psychol. Sci. 24(7): 1123-1132.

Kok BE, Fredrickson BL. 2010. Upward spirals of the heart: autonomic flexibility, as indexed by vagal tone, reciprocally and prospectively predicts positive emotions and social connectedness. Biol. Psychol. 85(3): 432-436.

Kraft TL, Pressman SD. 2012. Grin and bear it: the influence of manipulated facial expression on the stress response. Psychol. Sci. 23(11): 1372-1378.

Kroenke CH, Seeman T, Matthews K, Adler N, Epel E. 2012. Mood patterns based on momentary assessment of positive and negative moods over a day and coronary artery calcification in the CARDIA study. Psychosom. Med. 74(5): 526-534.

Kroenke K, Spitzer RL, Williams JBW. 2001. The phq-9. J. Gen. Intern. Med. 16(9): 606-613.

Lambiase MJ, Kubzansky LD, Thurston RC. 2015. Positive psychological health and stroke risk: the benefits of emotional vitality. Heal. Psychol. 34(10): 1043.

Liu B, Floud S, Pirie K, Green J, Peto R, Beral V. 2016. Does happiness itself directly affect mortality? The prospective UK Million Women Study. Lancet 387(10021): 874-881. 
Mancuso CA, Choi TN, Westermann H, Wenderoth S, Hollenberg JP et al. 2012. Increasing physical activity in patients with asthma through positive affect and self-affirmation: a randomized trial. Arch. Intern. Med. 172(4): 337-343.

Marsland Al, Pressman S, Cohen S. 2007. Positive affect and immune function. Psychoneuroimmunology: 761-779.

Maxwell SE, Lau MY, Howard GS. 2015. Is psychology suffering from a replication crisis? What does "failure to replicate" really mean?. Am. Psychol. 70(6): 487.

McNair DM, Lorr M \& Droppleman LF (1971). Manual for the profile of mood states. San Diego, CA: Educational and Industrial Testing Services.

Middleton RA, Byrd EK. 1996. Psychosocial factors and hospital readmission status of older persons with cardiovascular disease. J. Appl. Rehabil. Couns. 27(4): 3-10.

Moskowitz JT. 2003. Positive affect predicts lower risk of AIDS mortality. Psychosom. Med. 65(4): $620-626$.

Moskowitz JT, Carrico AW, Duncan LG, Cohn MA, Cheung EO et al. 2017. Randomized controlled trial of a positive affect intervention for people newly diagnosed with HIV. J. of Consult. and Clin. Psychol. 85(5): 409-423.

Moskowitz JT, Epel ES, Acree M. 2008. Positive affect uniquely predicts lower risk of mortality in people with diabetes. Heal. Psychol. 27(1): S73-82.

Mroczek DK, Spiro A, Griffin PW, Neupert S, Schaie KW, Carstensen LL. 2006. Social influences on adult personality, self-regulation and health. Social structures, aging and self-regulation. pp. 69-84. New York: Spring.

Mroczek DK, Stawski RS, Turiano NA, Chan W, Almeida DM. 2013. Emotional reactivity and mortality: longitudinal findings from the VA Normative Aging Study. Journals of Gerontology Series B: Psychol. Sci. and Soc. Sci. 70(3): 398-406.

Murphy SL, Xu J, Kochanek KD, Curtin SC. 2017. National vital statistics reports deaths: final data for $2015.66(6)$. 
Nater UM, Hoppmann C, Klumb PL. 2010. Neuroticism and conscientiousness are associated with cortisol diurnal profiles in adults- role of positive and negative affect. Psychoneuroendocrinology 35(10): 1573-1577.

Nater UM, Rohleder N, Schlotz W, Ehlert U, Kirschbaum C. 2007. Determinants of the diurnal course of salivary alpha-amylase. Psychoneuroendocrinology 32(4): 392-401.

Nefs G, Pop VJM, Denollet J. 2016. Depressive symptoms and all-cause mortality in people with type 2 diabetes: a focus on potential mechanisms. Br. J. Psychiatry 209(2): 142-9.

Nefs G, Pouwer F, Denollet J, Kramer H, Wijnands-van Gent CJM, Pop VJM. 2012. Suboptimal glycemic control in type 2 diabetes: a key role for anhedonia?. J. of Psychiatric Res. 46(4): $549-554$.

Neve J De, Oswald AJ. 2012. Estimating the influence of life satisfaction and positive affect on later income using sibling fixed effects. 109(49): 19953-19958.

Nickerson CA. 2018. Overstating the Effects of Loving-Kindness Meditation: Comment on Kok et al. (2013). Psychol. Sci. 29(3): 463-466.

Ogedegbe GO, Boutin-Foster C, Wells MT, Allegrante JP, Isen AM et al. 2012. A randomized controlled trial of positive-affect intervention and medication adherence in hypertensive African Americans. Arch. Intern. Med. 172(4): 322-326.

Ong AD, Benson L, Zautra AJ, Ram N. 2017a. Emodiversity and biomarkers of inflammation. Emotion 18(1): 3-14.

Ong AD, Kim S, Young S, Steptoe A. 2017b. Positive affect and sleep: a systematic review. Sleep Med. Rev. 35(607): 21-32.

Ong AD, Ram N. 2017. Fragile and enduring positive affect: implications for adaptive aging. Gerontology 63(3): 263-269.

Ostir G V, Markides KS, Peek MK, Goodwin JS. 2001. The association between emotional wellbeing and the incidence of stroke in older adults. Psychosom. Med. 63(2): 210-215. 
Park-Lee E, Fredman L, Hochberg M, Faulkner K. 2009. Positive affect and incidence of frailty in elderly women caregivers and noncaregivers: results of caregiver-study of osteoporotic fractures. J. Am. Geriatr. Soc. 57(4): 627-633.

Pennebaker JW, Mehl MR, Niederhoffer KG. 2003. Psychological aspects of natural language use: our words, our selves. Annu Rev Psychol 54: 547-577.

Peterson JC, Charlson ME, Hoffman Z, Wells MT, Wong SC et al. 2012. A randomized controlled trial of positive-affect induction to promote physical activity after percutaneous coronary intervention. Arch. Intern. Med. 172(4): 329-336.

Peterson JC, Czajkowski S, Charlson ME, Link AR, Wells MT et al. 2013. Translating basic behavioral and social science research to clinical application: the EVOLVE mixed methods approach. J. Consult. Clin. Psychol. 81(2): 217-230.

Petrie KJ, Pressman SD, Pennebaker JW, Overland S, Tell GS, Sivertsen B. 2018. Which aspects of positive affect are related to mortality? results from a general population longitudinal study. Annals of Behav. Med.

Pressman SD, Cohen S. 2005. Does positive affect influence health? Psychol. Bull. 131: 925-971.

Pressman SD, Cohen S. 2012. Positive emotion word use and longevity in famous deceased psychologists. Heal. Psychol 31(3): 297-305.

Pressman SD, Gallagher MW, Lopez SJ. 2013. Is the emotion-health connection a "first-world problem"?. Psychol. Sci. 24(4): 544-549.

Pressman SD, Jenkins BN, Kraft-Feil TL, Rasmussen H, Scheier MF. 2017. The whole is not the sum of its parts: specific types of positive affect influence sleep differentially. Emotion 17(5):778-793.

Prinsloo S, Wei Q, Scott SM, Tannir N, Jonasch E et al. 2015. Psychological states, serum markers and survival: associations and predictors of survival in patients with renal cell carcinoma. $J$. Behav. Med. 38(1): 48-56. 
Radloff LS. 1977. The CES-D Scale: A self-report depression scale for research in the general population. Appl. Psychol. Meas. 1(3): 385-401.

Robles TF, Brooks KP, Pressman SD. 2009. Trait positive affect buffers the effects of acute stress on skin barrier recovery. Health Psychol. 28(3): 373-378.

Russell JA. 1980. A circumplex model of affect. J. of Person. and Soc. Psychol. 39:1161-1178.

Schueller SM, Parks AC. 2012. Disseminating self-help: positive psychology exercises in an online trial. J. Internet Med. Res. 14(3): e63.

Seebach CL, Kirkhart M, Lating JM, Wegener ST, Song Y et al. 2012. Examining the role of positive and negative affect in recovery from spine surgery. Pain 153(3): 518-525.

Segerstrom SC, Sephton SE. 2010. Optimistic expectancies and cell-mediated immunity: the role of positive affect. Psychol. Sci. 21(3): 448-455.

Shirom A, Melamed S, Berliner S, Shapira I. 2009. Aroused versus calm positive affects as predictors of lipids. Heal. Psychol. 28(6): 649-659.

Shirom A, Toker S, Jacobson O, Balicer RD. 2010. Feeling vigorous and the risks of all-cause mortality, ischemic heart disease, and diabetes: a 20-year follow-up of healthy employees. Psychosom Med 72(8): 727-733.

Sims TL, Carstensen LL. 2014. The elusiveness of a life-span model of emotion regulation. ISSBD Bul. 38(3):30-32.

Sims T, Tsai JL, Koopmann-Holm B, Thomas E a C, Goldstein MK. 2014. Choosing a physician depends on how you want to feel: the role of ideal affect in health-related decision making. Emotion 14: 187-192.

Smith AM, Stuart MJ, Wiese-Bjornstal DM, Gunnon C. 1997. Predictors of injury in ice hockey players. A multivariate, multidisciplinary approach. Am. J. Sports Med. 25(4): 500-507.

Steinhardt MA, Brown SA, Dubois SK, Harrison Jr L, Lehrer HM, Jaggars SS. 2015. A resilience intervention in African-American adults with type 2 diabetes. Am. J. of Heal. Behavior 39(4): $507-518$. 
Steptoe A, Wardle J. 2011. Positive affect measured using ecological momentary assessment and survival in older men and women. Proc. Natl. Acad. Sci. 108(45): 18244-18248.

Steptoe A, Wardle J, Marmot M. 2005. Positive affect and health-related neuroendocrine, cardiovascular, and inflammatory processes. Proc. Natl. Acad. Sci. 102(18): 6508-6512.

Strand EB, Kerns RD, Christie A, Haavik-Nilsen K, Klokkerud M, Finset A. 2007. Higher levels of pain readiness to change and more positive affect reduce pain reports - A weekly assessment study on arthritis patients. Pain 127(3): 204-213.

Thayer JF, Lane RD. 2000. A model of neurovisceral integration in emotion regulation and dysregulation. J. Affect. Disord. 61: 201-216.

Tsai JL. 2007. Ideal affect: cultural causes and behavioral consequences. Perspect. Psychol. Sci. 2: $242-259$.

Usala PD, Hertzog C. 1989. Measurement of affective states in adults: evaluation of an adjective rating scale instrument. Research on Aging. 11(4): 403-426.

Versteeg H, Pedersen S, Erdman R, van Nierop J, de Jaegere P, van Domburg R. 2009. Negative and positive affect are independently associated with patient-reported health status following percutaneous coronary intervention. Qual. Life Res. 18(8): 953-960.

Ware Jr JE, Sherbourne CD. 1992. The MOS 36-item short-form health survey (SF-36): I. conceptual framework and item selection. Medical Care 30(6): 473-483.

Watson D, Clark LA, Tellegen A. 1988. Positive and negative affect schedule (PANAS). J. Pers. Soc. Psychol. 54: 1063-1070.

Whillans AV, Dunn EW, Sandstrom GM, Dickerson SS, Madden KM. 2016. Is spending money on others good for your heart?. Health Psychol. 35(6): 574-583.

Whitehead BR. 2016. Health behaviors in older adults: Considering age, affect, and attitudes. $J$. Health Psychol.

Wilson TE, Weedon J, Cohen MH, Golub ET, Milam J et al. 2017. Positive affect and its association with viral control among women with HIV infection. Heal. Psychol. 36(1): 91-100. 
Zautra AJ, Johnson LM, Davis MC. 2005. Positive affect as a source of resilience for women in chronic pain. J. Consult. Clin. Psychol. 73(2): 21-220.

Zhang Y, Han B. 2016. Positive affect and mortality risk in older adults: A meta-analysis. PsyCh journal. 5(2): 125-138. 